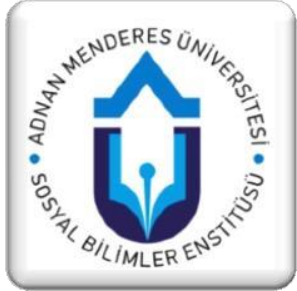

Araștırma Makalesi
Makale Geçmiși
Başvuru Tarihi: 08.06.2021
Kabul Tarihi: 30.09 .2021

\section{Üretim Süreçleri ve Atık Bakımından Ayakkabı Sektörünün Çevreye Etkisi ve Geri Dönüşüm Uygulamaları}

\author{
Havva Meryem IMRE ${ }^{1}$
}

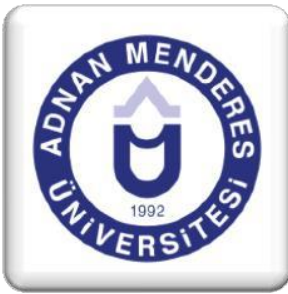

\author{
Research Article \\ Article History \\ Date of Application: 08.06.2021 \\ Acceptance Date: 30.09 .2021
}

Özet

Yeni endüstri çağında bir ürünün yaşam döngüsü çevresel bir sorun olarak ele alınmaktadır. Ayakkabı gibi farklı parçaların birleşmesi ile oluşan ürünlerin çevreye etkileri, kullanılan malzemelerin özelliklerine göre değişmektedir. Ayakkabının üretim aşamasında ve kullanımından sonra oluşan atığının bertaraf edilmesi ve üretim süreçlerinin iyileştirilmesi çalışmalarının hızlandırılması gerekmektedir. Ayakkabının yeniden kullanımı, geri dönüşüm faaliyetleri ile birlikte biyolojik parçalanabilen malzemelerin geliştirilmesi önem oluşturmaktadır. Yaşam döngüsünü tamamlamış olan ayakkabının atık olarak çevreye vereceği zararı üretim aşamasında kontrol edebilmek, sürdürülebilir malzemeler ve geri dönüşüm uygulamaları ayakkabı endüstrisi için önemli bir konudur.

Bu çalışmada ayakkabı üretimi sırasında ve kullanım sonrasında oluşan atık malzemelerinin özellikleri, çevre üzerindeki olumsuz etkiler araştırılmış ve bilgiler bir araya getirilerek, geri dönüşüm çalışmalarından örnekler verilmiştir. Yöntem olarak literatür araştırması ve basılı kaynak taraması yapılarak ayakkabı üretim süreçlerinin, malzemelerinin ve atıkların iyileştirmesi konusunda çalışmalar ve örneklerden bazıları incelenmiştir. Araştırmanın ayakkabı endüstrisinin üretiminde kullanılan malzemelerin çevreye verdiği zarar, iyileştirme ve geri dönüşüm çalışmaları hakkında farkındalık yaratabileceği düşünülmektedir.

Anahtar Kelimeler: Ayakkabı, Atık, Çevresel sorun, Geri dönüşüm

Jel Kod: L67, Q53, Q56

Enviromental Effects of the Shoe Sector in Terms of Manufacturing Processes, Waste and Recycling Applications

\begin{abstract}
In the new industrial age, the life cycle of a product is considered as an environmental issue. The environmental effects of products formed by the combination of different parts, such as shoes, vary according to the properties of the materials used. It is necessary to accelerate the efforts to eliminate the waste generated during the production phase and after the use of the shoes and to improve the production processes. It is important to reuse shoes and to develop biodegradable materials together with recycling activities. Being able to control the damage that a shoe which has completed its life cycle will cause as waste to the environment,sustainable materials and recycling practices is an important issue for the shoe industry.

In this study, the properties of waste materials formed during shoe production and after use, the negative effects on the environment were investigated and examples from recycling studies were given by bringing together the information. Literature research and printed source scanning were used as methods in examining some of the studies and examples on the improvement of shoe production processes, materials and wastes. It is thought that the research can raise awareness about the environmental damages, improvement and recycling studies on materials used in the production of the shoe industry.
\end{abstract}

Keywords: Shoes, Waste, Environmental problem, Recycling

Jel Code: L67, Q53, Q56

\footnotetext{
${ }^{1}$ Sanatta Yeterlik Programı Öğrencisi, Haliç Üniversitesi Sosyal Bilimler Lisansüstü Eğitim Enstitüsü, Tekstil ve Moda Tasarım Ana Bilim Dalı, havvameryemimre@ogr.halic.edu.tr, ORCID:0000-0002-5308-1217.”Ayakkabı Tasarımında Kullanılan Yenilikçi Tekstiller ve Çevreci Yaklaşımla Bir Model Önerisi” başlıklı Sanatta Yeterlik tezinden türetilmiştir.
} 


\section{Giriș}

Ayakkabı endüstrisi, üretim aşamasında malzeme verimliliğini artırmanın yanı sıra, ayakkabı üretiminde sürdürülebilir olmayan ve atık olarak çevreye vereceği zararlardan dolayı bazı malzemelerin kullanımını ortadan kaldırmak için çalışmalar yapmaktadır. Bu iyileştirme çalışmaları, üretim sürecinde sağlanan çevresel kazanımlar, ayakkabı tasarımı ve hızla değişen moda olgusu içerisinde ayakkabı ürünlerine olan talebin artmasıyla istenilen sonucu elde edememektedir. Bilindiği gibi, özellikle spor ayakkabıların kullanım ömrü diğer klasik ayakkabılara oranla daha kısadır. Kullanım süreçleri moda eğilimlerinin bir sonucu olarak giderek azalmaktadır.

Bunun sonucu olarak, ayakkabıların işlevsel ömrü bittiğinde ortaya bir atık akışı çıkar ve bunlar genellikle çöplüklere atılır. Tasarımcı, üretici ve kullanıcı olarak, ayakkabı endüstrisinin kullanım ömrü sonunda atıklarının geri dönüştürülmesi ve geri kazanımına yönelik araştırmalar hızla gelişmektedir ve uygulama alanları oluşturulmaktadır.

\section{Ayakkabı Malzemeleri ve Üretim}

Ayakkabı sektörü, çok farklı özelliklerde malzemelerin kullanıldığı farklı modellerin üretildiği bir üretim alanıdır. Deri, sentetik malzemeler, kauçuk, tekstil malzemeler en çok kullanılan malzemelerdir. Günümüzde ise bu malzemeler arasına biyo malzemeler ve geri dönüşüm malzemeleri de eklenmiştir. Bir ayakkabıyı üretirken neredeyse 40 farklı malzeme bir araya getirilmektedir ( Harvey, 1982). Ayakkabının ürün çeşitliliği, farklı modellerin üretilmesi, talep fazlalı̆̆ı ayakkabının yaşam döngüsünü olumsuz yönde etkilemiştir. Ayakkabının kısa yaşam döngüsü ayakkabı üretiminin artmasına yol açmaktadır. Bu üretim fazlalığı ise daha fazla atığın ortaya çıkarak kısa zamanda çıkmasına çevre ile buluşacağı anlamına gelmektedir.

\subsection{Atık Malzeme Tanımı ve Özellikleri}

Sanayileşme, kentleşme ve iklim değişikliği, doğal kaynakların bilinçsiz tüketiminin etkisiyle üretim aşamasında ve tüketim sonucunda atıklar oluşmaktadır. Tüketim şekli, üretim süreçleri, malzemelerin kimyasal ve fiziksel özelliklerine göre katı, sıvı ve gaz olarak sınıflandırılabilir. Ayakkabı sektörüne katı atıklar açısından bakıldığında, üretim sonucunda artık üretime faydası olmayan insan ve çevreye olumsuz etkisinden dolayı bertaraf edilmesi zorunlu olan maddelerdir. Hangi sektörden ortaya çıkışına bakılmaksızın atık, kullanım özelliği kalmamış ve ekonomik değeri olmayan malzemelerdir (Read,1999). Bu atıklar endüstriyel uygulamalardan kaynaklanan atıklardır. Üretim süreçleri boyunca ve endüstriyel işlemler sonucunda oluşan atıkları içermektedir (Sayar, 2012).

Ayakkabı sektöründe deri, çevre açısından önemli bir atık ve kirleticidir. Derinin tabaklanma ve ürün haline gelme sürecinde atıkların özellikleri maddelerin yapılarına göre değişmektedir (Downing, 1981). Deri sanayi ekolojik etkileri açısından etkin bir şekilde denetlenmektedir. Derinin ürün haline gelmesi, ürünün şekline, üretim biçimine ve kullanılan teknolojiye göre kayı, sıvı ve gaz atık olarak açığa çıkmaktadır (8. Kalkınma Planı, 2001). Ayakkabı sektöründe atık malzeme azaltmak için öncelikli olarak atığın ortaya çıkış sebepleri belirlenerek, atık şeklini tanımlamak, üretim sürecinde ortaya çıkan fiziksel atık miktarı ve sürecini saptamak önemli konuların başında gelmektedir. Özellikle tabaklama işlemi zaman içerisinde bitkisel işlemden uzaklaşıp, hız ve serilik açısından krom ile yapılmaya başlanmıştır. Bu işlem bitkisel tabaklama işleminden daha fazla su harcamaktadır ( Topbaş vd.1998). Krom tabaklama sürecinde kromun deride tutunamayan yaklaşık \%20-40 lık kısmı atık olarak çevresel problem oluşturmaktadır (Nriagu vd.1988). Üretim sürecinde ve kullanım sonucunda oluşan atıkların yeniden ele alınarak, bitkisel tabaklama yönteminin 
geliştirilmesi, alternatif malzemeler ile çalışmaların devamlılığı doğal kaynak tüketimi açısından önemli çalışmalardır (Dix, 2001).

Ayakkabı üretiminde katı atıklar genellikle kesim işleminde meydana gelmektedir. Deri malzeme kullanımında derinin kalitesi ve ayakkabı modelinin stampasına ( modelin kesim kalıb1 ) göre verimlilik esası etkili olmaktadır. Verimlilik, doğal bir malzeme olan derinin her parçasının ve her tarafının aynı özellikleri göstermediğinden atık oranlarında standart bir sonuç elde edilememektedir. Bu değişkenliklere göre bakıldığında deri ayakkabı üretiminde atık oranı \%25-45 arasında farklılık bulunmaktadır (Şekil 1). Deri konusunda üretim aşamasında atık oluşmaması konusunda çalışmalar yapılmasına rağmen seçeneklerin kısıtlı olması ilerlemeyi zorlaştırmaktadır(http://cec-footwearindustry.eu/policies/environmentalpolicy/).

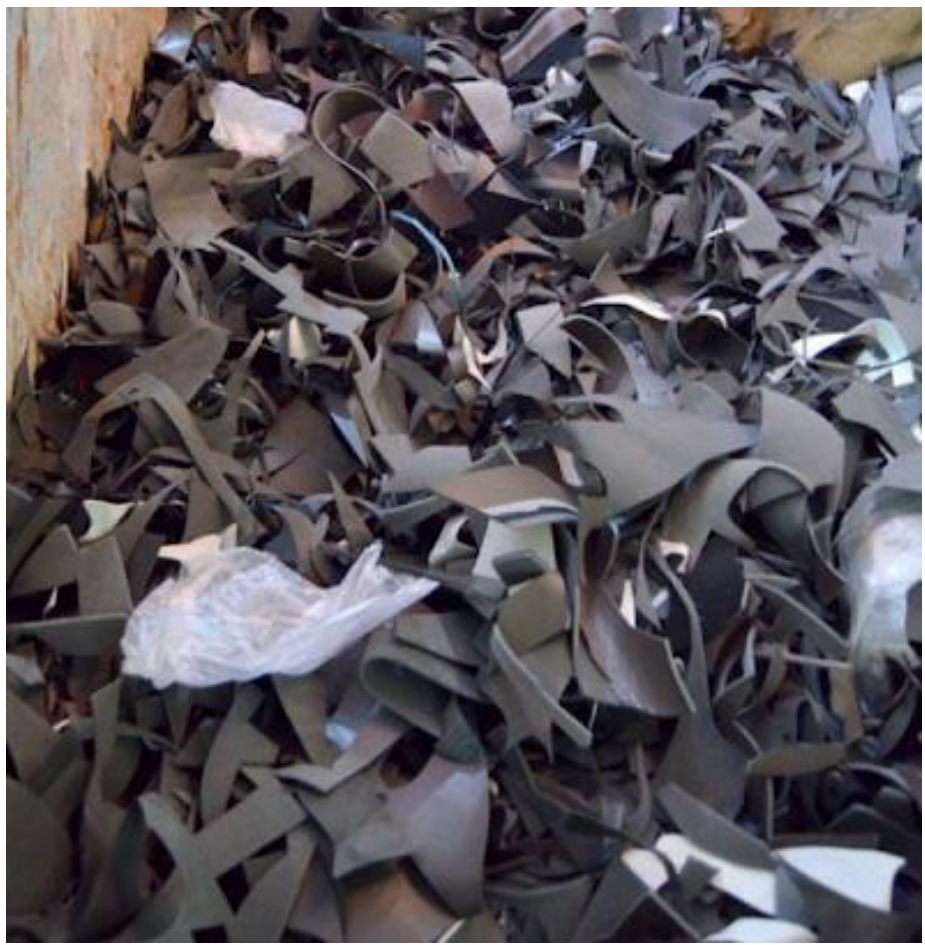

Şekil 1:Deri atıkları (www.geredederi.com) Erişim Tarihi: 04.04.2021

Kesim işlemini verimli hale getirebilmek ve atık miktarını azaltmak için bilgisayarlı sistemler kullanılmaktadır. Sentetik malzemeler için bu sistem verimliliği arttırarak, atık miktarını azaltmaktadır. Ayakkabı üretiminde özellikle spor ayakkabılarda saya ( ayakkabı üst kısmı) malzemesi, kullanılan sentetik ipliklerden yapılan tekstiller fire oranlarını en aza indiren malzemeler olarak kullanılmaktadır. Bu malzemeler kullanım ömürleri sonrasında da ayrıştırılarak geri dönüşüm ile tekrar üretime ilave edilmektedir. Bunun dişında termo plastik kalıplamada atıklar oluşmaktadır (Şekil 2). Bu işlemden doğan atıklar geri dönüşüme uygun malzemeler olarak öğütülüp tekrar ürün kullanımına uygun hale getirilmektedir. 


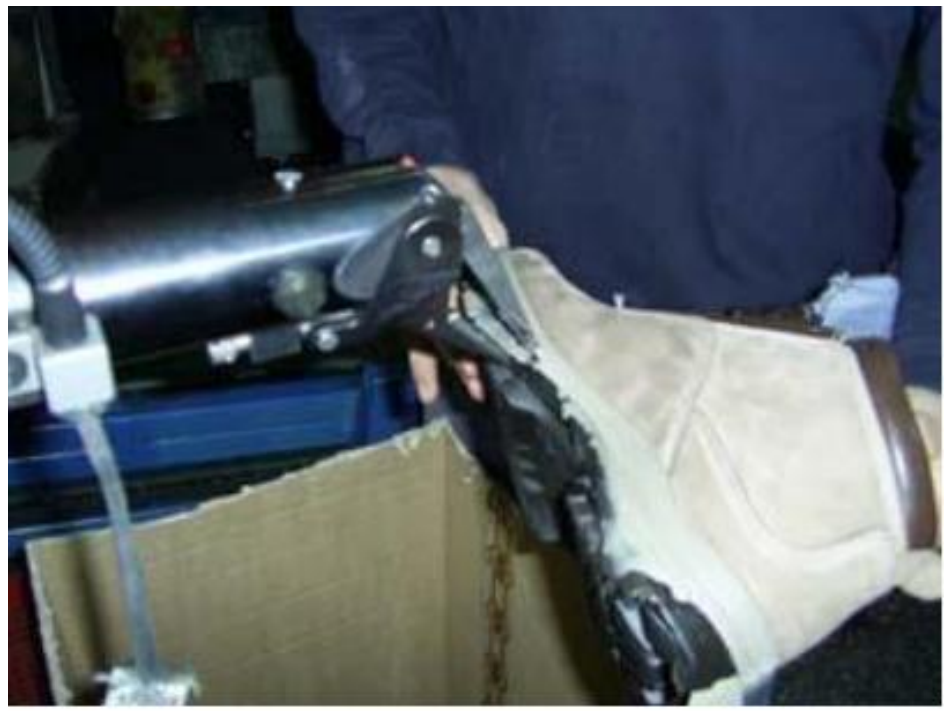

Şekil 2:Termoplastik taban çapak temizlemede atık.

(https://tekstilbilgi.net/enjekte-taban-montaji.html) ErişimTarihi: 02.03.2021

Kullanım ömrünü tamamlamış tabanlar, geri dönüşüm uygulaması süreçleri doğrultusunda malzemeler özelliklerine göre ayrılmaktadır (Şekil 3). Daha sonra granül boyutlarına getirilerek işslenerek yeniden kullanıma kazandırılmaktadır.

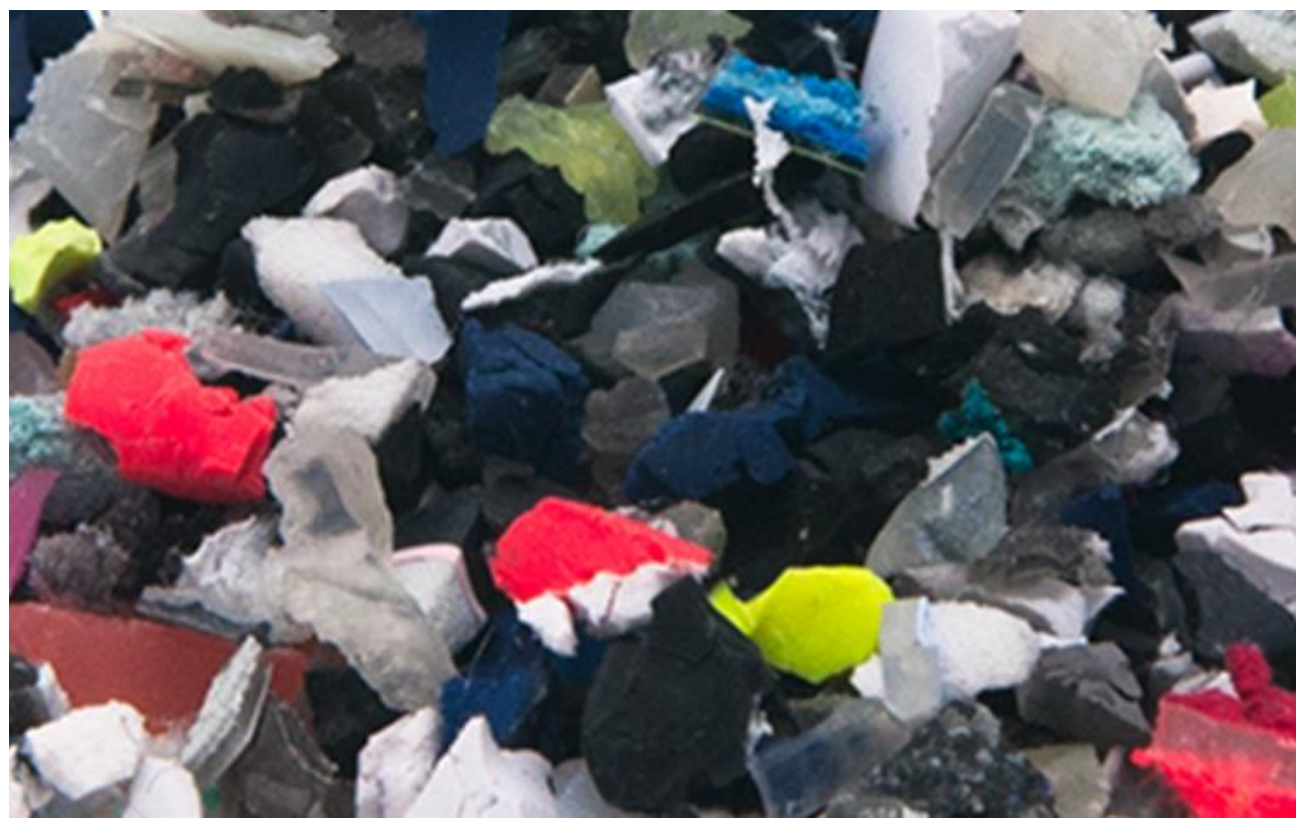

Şekil 3: Kullanım ömrünü tamamlamış tabanların geri dönüşüm için hazırlanması.

(https://www.nikegrind.com/rubber/)Erişim 10.03.2021.

Çevre ile uyumlu deri üretimi konusunda çalışmaların geliştirilmesine de çalışılmaktadır. Bu çalışmalar Eko-deri, Bio-deri, Vegan-deri gibi alternatif malzemeler ile üretime katkı sağlamaktadır. Bu çalışmalar ile beraber, çevre ile uyumlu üretim teknolojileri, atık kontrolü, yeni tabaklama yöntemleri ayakkabı sektöründe geliştirilmesi gereken önemli konulardır ( Thanikaivelan ve ark. 2004). 


\subsection{Ayakkabı Sektöründe Atıkların Çevreye Etkisi}

Ayakkabı sektöründe malzeme ve üretim süreçleri ile ilgili çevresel sorunlar bulunmaktadır. Üreticiler daha çok çevresel etki olarak kimyasallar ve katı atıklar olarak düşünmektedir. Son zamanlarda çevreye zararlı olan en büyük problemin deri tabaklama işleminde kullanılan krom kanserojen etkisinden dolayı önemli bir konumdadır (Sreeram ve Ramasami,2003). Sentetik malzemeler, deri kaplamalar, yapıştırıcılar, temizleyicilerde kullanılan çözücüler diğer uçucu organik bileşikler hava kirletici olan ozon oluşumuna neden olmalarından dolayı ayakkabı sektöründe önemli atık malzemelerdir. Avrupa Birliği, çevresel etkileri daha düşük olan ayakkabı ürünlerini tanıtmak için, çevre dostu ve sürdürülebilir ayakkabı üretimi için Avrupa Ayakkabı Eko-Etiketi programını etkinleştirmiştir. Bu etiketin kullanılması için ayakkabı üretiminde istenilen ekolojik kriterlerin uygulanması gerekmektedir. Bu kriterler toksik kalıntı seviyelerini sınırlamak ve daha uzun kullanım ömrü olan ayakkabı üretimini teşvik etmek için konulmuștur (AB Commision Desicion,2002). Bu önlemlerin alınmasına karşın ayakkabının kullanım ömrü sonunda ortaya çıkan atıklar daha büyük çevresel sorundur. Her yıl milyonlarca çift ayakkabı üretilmektedir. 2019 yılında dünyada 24.3 milyar çift ayakkabı üretilmiştir. Ayakkabı üretim adetlerine ve yaşam döngülerinin kısa olması düşünüldüğünde çöp alanlarına giden ayakkabılar atık olarak ciddi çevresel sorunlar oluşturmaktadır (https://www.statista.com/statistics/1044823/global-footwear-productionquantity/ErișimTarihi: 22.03.2021).

Ayakkabı atıklarının çöp alanları yerinde geri dönüşüm malzemesi olarak kullanılmak üzere depolanması için atık depolama alanları faaliyete geçirilmiştir (Burnley,2001). Biyolojik olarak parçalanabilen, doğal tekstiller, doğal kauçuk gibi malzemeler ayrıştırılarak yeniden kullanım için geri dönüşüm uygulamasında kullanılmaktadır.

Ayakkab1 üretiminde kullanılan kimyasallar, üretilen karbon ayak izinin \%30unu oluşturmaktadır (https://theshoeindustry.weebly.com/enviromental-impact.Erișim Tarihi 16.01.2021).

Ayakkabının yaşam döngüsünün ilk ve son aşamasında toksin, kimyasal ve fosil yakıtların çevreye sızması doğaya ve doğada yaşayan birçok canlıya ve insan sağlığına zarar vermektedir. Bir çift ayakkabının üretimi ortalama 30 kilogram karbondioksit ortaya çıkarmaktadır. Ayakkabının yaşam döngüsünün son adımı giyildikten ve eskidikten sonra atık hale geldiğinde çevre ve doğaya etkisi daha da fazlalaşmaktadır.

Ayakkabı endüstrisi dünyanın en büyük endüstrilerinden birisidir. Aynı zamanda dünya çapındaki karbondioksit emisyonuna en büyük katkıyı sağlayan endüstri olarak bilinmektedir. Amerika'da "National Recycling Coalition" isimli kuruluş spor ayakkabıların geri dönüşüm ve sürdürülebilir kalkınma çalışmalarına destek vermektedir ( https://nrcrecycles.org/, Erişim Tarihi:10.01.2021).

\subsection{Ayakkabının Üretim Süreçlerinin Çevreye Etkisi}

Çevreye etki açısından ayakkabının üretim aşamaları önemlidir. Ayakkabının üretilmesi için gerekli olan makinelerin çalışması için fosil yakıt kullanılması ile sera gazı üretimi gerçekleşmektedir (www.theshoeindustry.weebly.com). Bu kaynaklardan biri de kömürdür. Karbondioksit üretilmesi, üretimde kullanılan trimbofenol, klorlu parafin gibi kimyasalların da toprağa sızmasıyla çevreye verdiği olumsuz etkileri bilinmektedir (Sameer, 2020). Ayakkabı sektöründe sentetik malzemeler $\% 57$, deri $\% 25$ ve tekstil malzemeler $\% 18$ olarak kullanılmaktadır. Bu değerlendirmeler 2016 yll verileri 2005-2010 yllı aralı̆̆ındaki veriler ile karşılaş̧tırılarak 2020-2030 yıllarına göre tahminler çıkarılarak oluşturulmuştur "(Quantis,2018).Ayakkabı üretim süreçlerinin iyileştirilmesi ve kullanılan 
malzemelerin geri dönüşümde kullanımları önemli konular olarak ele alınmaktadır. Küresel ayakkabı endüstrisi ayakkabının yaşam döngüsünde yedi farklı aşama yaklaşımı kullanılmıştır. Her bir yaşam döngüsü aşaması için sera gazı (GHG) emisyonları ölçüldüğünde, küresel emisyonun \%1.4 ünün sorumlusu olarak ayakkabı endüstrisi görülmektedir. Bu değer 700 milyon ton Carbon (CO) ifade etmektedir ve emisyonların $\% 60$ tan fazlasının üretim ve hammadde çıkışlı olduğunu belirtmektedir. "Ayakkabının yaşam döngüsündeki 7 aşama ve değerleri şu şekildedir”.

a) Hammadde $\% 20$

b) Hammadde İsleme \%14 ( tabaklama, iplik, dokuma)

c) Üretim \% 43 (Kesim, dikim, vb)

d) Montaj \% 20 (malzemelerin birleştirilmesi)

e) Ambalaj \% 1 ( Kutulama)

f) Nakliye \%2 (Mă̆azalara sevkiyat)

g) Atıkyok etme \% 7 (yakma veya depolama)

Çevresel etkiyi azaltmak için en önemli çalışma kullanılmış ayakkabıların çöp sahalarına gitmemesini sağlamak için geri dönüşüm çalışmalarına ve üretim süreçlerinin iyileştirilmesine hız verilmesidir.

Atık yönetiminde geri dönüşüm çalışmalarının sonuçlarını görebilmek için izlenecek yolların sistemli bir yöntem içermesi önemlidir. Atıkların imha edilmesi kontrollü bir şekilde gerçekleştirilmelidir. Doğaya ve insana verdiği zararın en aza indirilmesi ve atık ürünlerin geri dönüşümü doğru planlanmalıdır (Cheeseman,2002).

\section{Atıkların Geri Dönüşüm Malzemeleri Olarak Kullanımı}

Doğal kaynakların bilinçsiz kullanım sonucu ile tükenme noktasına gelmesi, atıkların geri dönüşüm sisteminde işlenerek tekrar kullanıma hazır hale gelmesi önem kazanmıştır. Sanayi devrimi ile temeli atılan tüketim kültürü son yıllarda hızlı moda anlayışı çerçevesinde hızlanmıştır.

90'lı yılların başında plastik tüketiminin artması ve buna bağlı çevre sorunlarının gözle görülür seviyelere gelmesi sonucu popülerleşen “geri dönüşüm” faaliyetleri, 90'lardan bu yana tekstil ve ayakkabı sektörlerinde de geniş bir biçimde uygulanmaktadır. Üretilmiş bir ürünü geri dönüştürerek yeniden üretime sokmanın da oldukça maliyetli olması nedeniyle geri dönüşüm ihtiyacı oluşana kadarki süreçte; kullanılan ürün miktarlarını azaltmak çevreye daha az zarar verecek ürünler kullanmak, ihtiyaçların iyi belirlemek ve ürünlerin yaşam döngüsünü uzatmak adına başka birtakım uygulamaları hayata geçirmek yönünde çalışmalara başlanmıştır.

Ayakkabı tabanında kullanılan malzemelerden biri olan Termoplastik kalıplamada atıkların öğütülmesi konusunda çalışılmaktadır. Bu materyaller için geri dönüşüm seçenekleri vardır fakat ticari düzeyde değildir. Bazı spor ayakkabı markaları taban malzemelerini geri dönüşümde kullanabilecek şekilde üretim süreçlerine ilave etmişlerdir. (No.56 The Footwear Industry and the Enviroment May 1999). Geri dönüşüm süreçleri taban malzemelerinde etkin olduğu kadar derinin geri dönüşüme uygunluğu çözülememiştir.

Ayakkabıların üretimi esnasında kullanılan kimyasallarının çözünerek toprak ve suya sızması sonucu doğaya verdiği olumsuz etkiyi azaltmak için bazı ayakkabı markaları geri dönüşüm programları oluşturmuştur. Bu programlardan biri "Ayakkabıyı Yeniden Kullan" sloganı ile hayata geçiren Nike markasıdır (https://recyclenation.com/2012/08/nike-reuseshoe-program/, Erişim: 10.01.2021). 
1990 yılında Nike, atık hale gelen ayakkabıların çevre üzerindeki olumsuz etkisini görerek, spor ayakkabıların toplanıp depolanarak, geri dönüşüm ile yeniden kullanılabilir hale getirme çalışmalarına başlamıştır. Geri dönüşüm ayakkabıyı dış taban, köpük orta taban ve tekstil saya olarak üç ana parçada işlemektedir. Kauçuk taban geri dönüştürülerek atletik oyun sahalarının zemininde, Nike Pegasus'un veya Jordan XX3'ün tabanında kullanılmıştır (Şekil 4). Nike firması bu geri dönüştürülmüş malzemeye Nike Grind adını vermiştir.

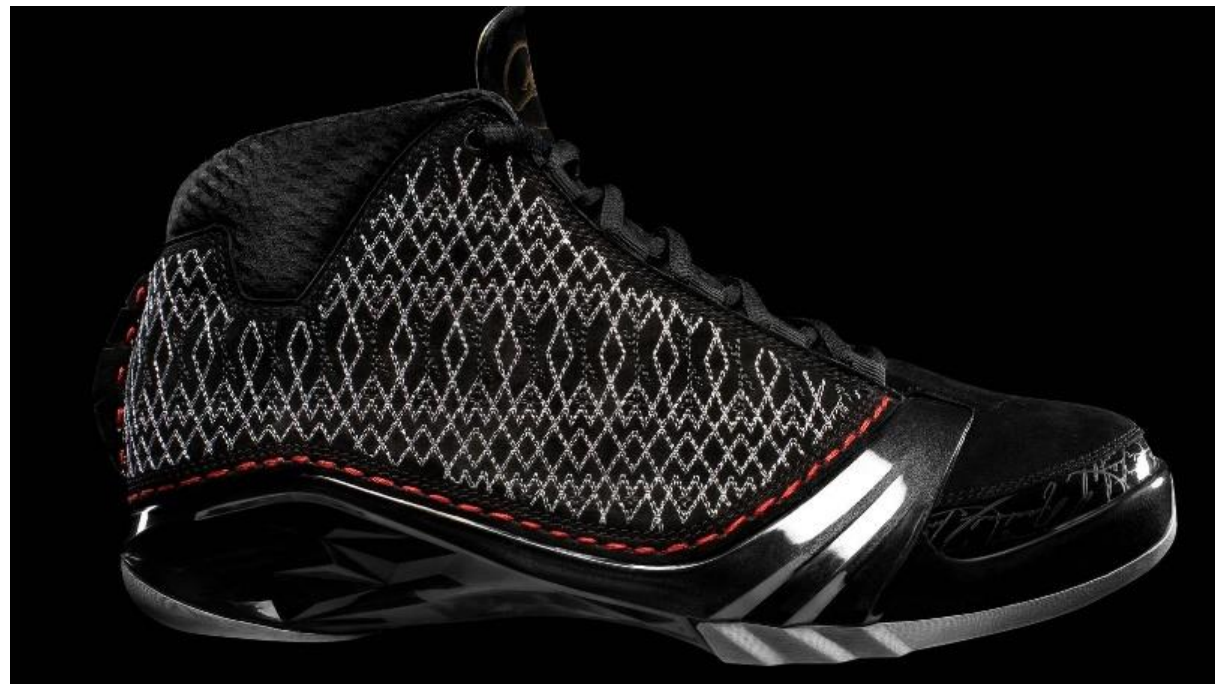

Şekil 4: Nike Jordan XX3 ayakkabı tabanında geri dönüşüm kauçuk kullanılmıştır.

https://news.nike.com/news/jordan-brand-launches-air-jordan-xx3 Erişim: 29.03.2021

Ayakkab1 üretimindeki deri ve sentetik atık malzemelerden saya, geri dönüştürülmüş kauçuktan taban yapılarak "Trash Talk" adı verilen basketbol ayakkabısı üreten Nike firması $\% 17$ daha az atık yaratmak için çalışmalarını hızlandırmıştır. 2020 yılı sonuna kadar da \%20 daha fazla atık malzeme kullanma hedefini yakalamıştır. Bu harekete "Düşünceli Tasarım" adını vererek daha çevreci bir marka ve daha fazla geri dönüştürülmüş malzeme kullanmaya odaklanmıştır (Şekil 5).

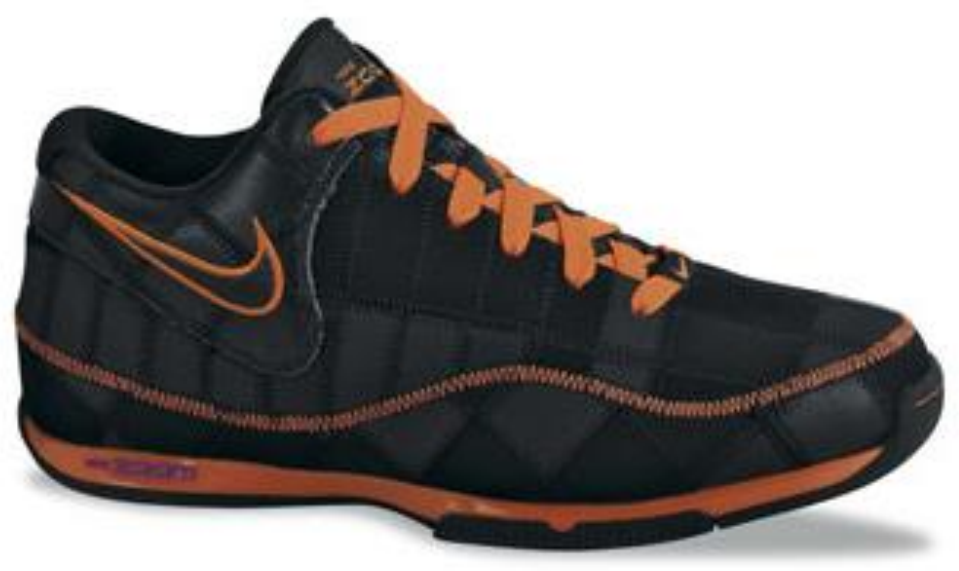

Şekil 5: Nike "Trash Talk” basketbol ayakkabısı, geri dönüşüm malzeme. 
Geri dönüşüm işlemleri hem zamansal hem de finansal açıdan oldukça maliyetli süreçlerdir. Geri dönüşüm işleminde işlenen malzemenin özelliklerinde kayıplar yaşanması nedeni ile aslında bu bir aşağı dönüşüm (downcycle) işlemidir (McDonough ve Braungart, 2002). Bu dezavantajları nedenleri ile geri dönüşüm yerine, atıl malzemenin hiçbir işleme sokulmadan o haliyle yeni üretim sürecinin hammaddesi olarak kullanılabildiği ileri dönüşüm süreçlerinin yaratılması da önemli bir çalışmadır. İleri dönüşüm, tasarımı merkezine almış bir dönüşüm yaklaşımı olarak diğer dönüşüm faaliyetlerinden ayrılmaktadır. İleri dönüşümle; geri dönüşümden çok daha düşük maliyetlerle, kapalı döngüye sahip, çevreye ve insana zararı en az seviyeye çekilmiş üretim süreçleri yaratmak mümkündür.

Ayakkabı sektörü üretim süreçleri ve kullanılan malzemeler konusunda doğayı kirletme performans1 yüksek endüstrilerden biri olduğundan ve bir çift ayakkabının karbon izi $\% 70$ malzeme ve üretim süreçlerinden kaynaklandığından geri dönüştürülmüş ve biyo temelli malzemelerin kullanılarak üretim süreçlerinin en uygun hale getirilmesine çalışılması konusunda Vivobarefoot firması önemli çalışmalar yapmaktadır(https://www.businessinsider.com/barefoot-shoes-vivobarefoot-sustainable2018-8,Erişim Tarihi:12.02.2021).

Geri dönüştürülmüş malzemelerden ayakkabı tasarımı yapan Vivobarefoot şirketi ise doğal kaynakların verimli kullanımına duyarlı çevre dostu geri dönüştürülmüş malzemeler ile insanın ayak anatomisine uygun kalite ve konforu yüksek ayakkabı tasarımlarına yoğunlaşmıştır. PET şişeleri geri dönüşümle eko-kanvas ve eko-süet kumaşlarını üreterek geri dönüşüm ve sürdürülebilir malzemeler konusunda ilerleme kaydetmiştir. Üründe bulunan yeniden kullanılabilecek parçaların tekrar ürüne katk1 sağlaması konusunda ki çalışmalar önem kazanmaktadır (Salustri, 2005).

Ayakkabı üretim atığını kullanarak \%50 geri dönüştürülmüş malzeme haline getiren Nike firması Nike air tabanı 2008 yılından beri kullanmaktadır. Air taban üretimi sırasında oluşan atıkların da \% 90'ından fazlasını üretimde tekrar kullanmaktadır (Şekil 6).

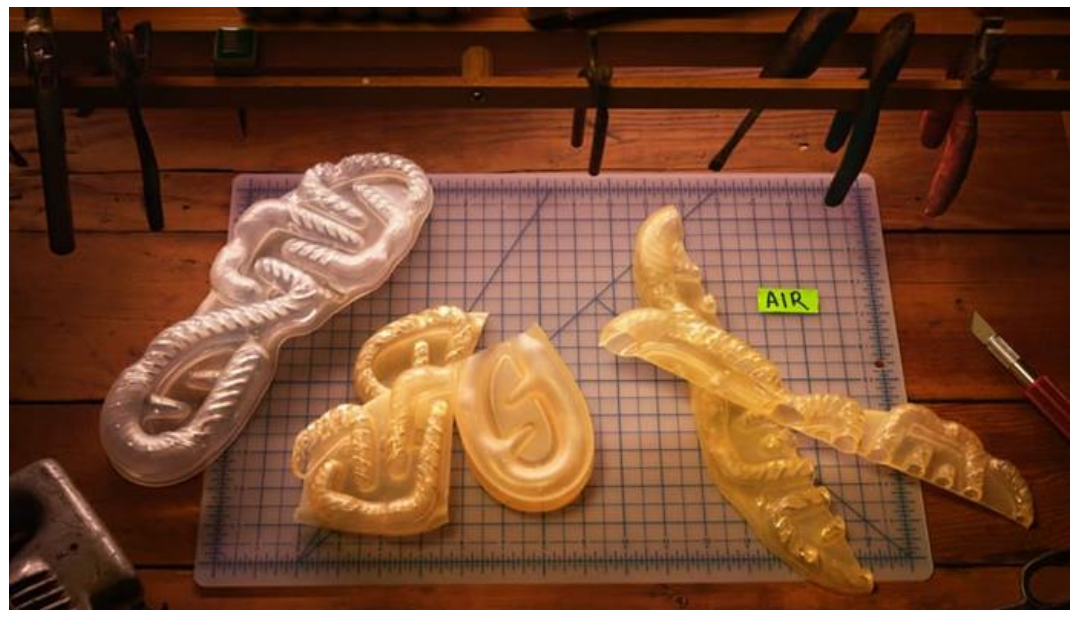

Şekil 6: Nike air taban. https://www.nike.com, Erişim Tarihi: 16.03.2021

Ayakkabı üretiminde kullanılan malzemeler atık bakımından değerlendirilerek tekrar üretime kazandırılmaktadır. Bununla beraber, yaşam döngüsünü tamamlayan ayakkabıların malzemeleri geri dönüştürülerek tekrar üretimde kullanılırken, müşteriyi çevre dostu ve sürdürülebilir üretim süreçleri hakkında bilgilendirme önem kazanmaktadır. Markalar, 
ürünleri konusunda bilgilendirme çalışmaları ile müşteri ilişkilerini güçlendirme çalışmaları yapmaktadir.

\section{Sonuç ve Öneriler}

Ayakkabı endüstrisinde atık yönetimi, etkili çözümler gerektiren önemli bir konudur. Çöp olarak doldurma veya yakma işlemi, çoğu ülkede atıklar için kullanılan önemli bir sistemdir. $\mathrm{Bu}$ yöntemlere rağmen, ayakkabı sektöründe katı atık yönetimi birçok ülke için ciddi bir sorun olmaya devam etmektedir. Atık problemi, üretim sürecinde ve kullanım süreci sonrası olarak ayrılmalı, verimli ve etkili bir atık yönetimi sistemi konusunda çalışmalar güçlendirilmelidir. $\mathrm{Bu}$ araştırma çerçevesinde ayakkabı sektöründe farklılık ve farkındalık oluşturmaya yönelik önerileri şu şekilde sıralayabiliriz.

Geri dönüştürülebilir malzemeler sınıflandırılarak yeni pazar ve kullanım alanlarının oluşturulması uzun vadede ayakkabı üreticileri arasında rekabeti daha etkili konuma getirecektir.

Bir ayakkabının geri dönüşüm sürecini geliştirmenin ilk adımı, tüketici sonrası ayakkabıları kullanım ömrü bittikten sonra belli noktalarda depolanmasını sağlamak olacaktır. Daha sonra malzemeleri ayrıştırma yöntem ve süreçleri belirlenmelidir.

Ayrıştırma işlemi için öneriler; kullanılabilir durumda olan ayakkabıları ayırıp tadilatlarını yaparak, giyilebilir duruma getirip ihtiyacı olan insanlara veya ülkelere göndererek sosyal sorumluluk projesi çerçevesinde değerlendirilebilir.

Geri dönüştürülmüş malzemeler veya kullanılabilir durumda olan ayakkabılar için yeni pazar arayışları oluşturarak ekonomik değere çevrilmesi çalışmalarına ağırlık verilebilir.

$\mathrm{Bu}$ konularda ayakkabı üreticilerinin projeler hazırlayarak yeni bir değer zinciri oluşturma fikrini geliştirecek çalışmalara yönelmeleri sektöre yeni bakış açısı kazandıracaktır.

Günümüzde, geri dönüşüm çalışmalarında gelişme ve ilerleme kaydedilmiş olmasına rağmen ileri dönüşüm faaliyetleri küçük adetli ve özel üretimlerle sınırlı kalmıştır. Bu yaklaşımın geri dönüşüm faaliyetleri gibi yaygın olarak kullanılması ve yöntemler oluşturulması konusunda çalışmalar yapılmalı ve desteklenmelidir.

Bu çalışmaları geliştirerek, ayakkabıların yaşam döngüsünü uzatarak, çevre dostu yaklaşım ile sürdürülebilir üretimi güçlendirmeyi hedefleyerek, ulusal ve uluslararası alanda ayakkabı atık yönetiminde farklı bakış açıları oluşturmanın sektöre katkı sağlayacağı düşünülmektedir. 


\section{Kaynaklar}

BURNLEY, S.(2001). The Impact of the European Landfill Directive on Waste Management in the United Kingdom, Resources, Conservation and Recycling, 32: 349-358.

CHEESEMAN, K.(2002).Waste Minimisation:a Practical Guide.2.Edition,Chadwick House Group. London. Ltd.ISBN.1904306047

COMMISSION DECISION.( 2002)./32/ec of 18 March 2002 on establishing revised ecological criteria for the award of the community eco-label to footwear and amending Decision

1999/179/EC.OJL.77/50.https://lex.europe.eu/LexUriServ.do?uri=OJ:L:2002:077:0050:0056 :EN:PDF

DIX,J.P. (2001).Chemical Developments Leading to Cleaner Production. Basf, World Leather, February-March. Germany.

DOWNING, A.L.(1981). Industrial Waste Water Treatment Course Notes, Delft. Holland.

HARVEY, A.(1982). Footwear Materials and Process Technology, Lasra Productions, New Zeland.

8. Kalkınma Planı. (2001). Deri Ve Deri Mamulleri Sanayi Özel İhtisas Komisyonu Raporu, Devlet Planlama Teşkilatı, Ankara

MCDONOUGH, W.and BRAUNGART,M. (2002).Remaking the way we make things: Cradle to cradle, North Point Press, New York.

NIRAGU,J.D. and NIEBOER,E.(1998). Chromium in The Natural and Human Environments, Wiley.Interscience Publication. Canada.ISBN:978-0-471-85643-6

READ, A. D. (1999). A Weekly Doorstep Recycling Collection, I had no Idea We Could Overcoming the Local Barriers to Participation. Resources, Conservation and Recycling, 26, $217-249$.

SAYAR, Ş. ( 2012). Sakarya İli Entegre Atık Yönetimi ve Ambalaj Atıklarının Geri Dönüşümü. Sakarya Üniversitesi, Fen Bilimleri Enstitüsü, Yüksek Lisans Tezi. Sakarya.

SREERAM, K.and RAMASAMI,T.(2003). Sustaining Tanning Process through Conservation Recovery and Better (PDF) End of Lifemanagement of shoes and the role of biogederble materials. https://www.researchgate.net/publicition/229015996 (Erişim Tarihi:23.03.2021).

THANIKAIVELAN, P. RAO, R. R. and NAIR, U. B. RAMASAMI,T.(2004).Progress And Recent Trends İn Biotechnological Methods For Leather Processing.

TOPBAŞ, M.T,BROHI,A.R,ve KARAMAN,M.R.(1998). Çevre Kirliliği,T.C. Çevre Bakanlığı Yayınları, Ankara.

SALUSTRI,F.A.(2005).Using Pattern Languages in Design Engineering, International Conference on Engineering Design, ICED O5 Melbourne, August 15-18.

SAMEER,M. (2020).Environmental Impact of Shoe Manufacturing Process, November DOI: 10.13140/RG.2.2.31678.72002 (PDF) (researchgate.net) 